\title{
Building an interactive platform for practical design projects between students and industries
}

\section{Sheng Qiu, Shou-xiang Jiang}

Institute of Textiles and Clothing, The Hong Kong Polytechnic University, Hong Kong, China.

\begin{abstract}
The advancement of information media and the convenience of the Internet have fostered the growth of web-based instruction, interactive functions, and resources available for participants to engage, interact, learn, discuss, and access without time and space constraints. This paper aims to provide an introduction on an interactive online platform which is beneficial for university-enterprise cooperation. Enterprises and students have more online and offline opportunities to gain a better mutual understanding and actively collaborate. Combined with the "learning to learn" theory, this sustainable platform can enhance the learning of students so that they learn capabilities over time through guidance and practical projects exercise.
\end{abstract}

Keywords: Design education; online platform; learning to learn; practical design. 


\section{Introduction}

Nurturing the ability of students to learn has been widely regarded as one of the important objectives of Hong Kong's education reform. The Curriculum Development Council (2001) also pointed out the crucial role of "learning to learn: the direction of curriculum development" in a conference document. Hence, in order to equip students so that they can face the challenges of the 21 st century, school curriculum must help students to establish positive values and attitudes, and encourage the spirit of lifelong learning, so as to learn how to learn, and cultivate a variety of general abilities to acquire and construct knowledge and lay the foundations for the advancement of humankind.

To achieve this goal, it is necessary to impart knowledge on "learning to learn" and the skills to do so. In an era that continuously innovates knowledge, students not only need to gain knowledge, but also master learning skills, so that they can guide themselves through continuous learning and become lifelong learners after leaving school.

Universities lack a platform to integrate and sustain enterprise resources, while students and teachers lack the channels to directly access enterprise resources. Opportunities for students to contact enterprises are still limited, and they may lack the skills for effective communication and cooperation with enterprises, as well as the ability to implement practical work. For enterprises, the school lacks a platform through which they can actively seek cooperation and understand students, as the lack of trust can be problematic when they are in a cooperation situation. The current school-enterprise cooperation model faces numerous limitations in resources, coverage and globalization. Thus, a platform for schools and enterprises is timely and needed. Effective communication is expected to be carried out in real time and increase production efficiency. Moreover, students need a "learning to learn" type of guidance for working with enterprises, so that they can inspire to aspire and develop a sense of purpose in cooperating with the industry through guidance, which can improve their success and learning experiences.

Therefore, we build an interactive platform for students and enterprises to solve the problems mentioned above. In this project, we explore the entire project management process for students on the platform, which provides them with "learning to learn" guidelines to engage in this sustained process.

\section{Aim of the Study}

This project aims to build a sustainable interactive online platform to encourage students and enterprises to participate in a practical project collaboration in fashion and textile design, which can improve the "learning to learn" capabilities of students and provide global business cooperation resources, so that students can receive professional "learning to learn" guidelines 
and have the opportunity to cooperate with enterprises to design products during their study period. This project can enhance "learning to learn" capabilities, and communication and cooperation skills with the industries. The knowledge that students gain will be truly in line with the needs of the enterprise and the market. Students could also gain the ability to learn in a new environment and adapt to it, which can encourage them to be a more autonomous, effective and adaptive learner.

Figure 1 shows that at the beginning, the motivation to learn is instilled in students, and then they develop a sense of purpose and make plans. Then, students are guided to combine metacognitive strategies in practice. In the end, students will gain knowledge, and new skills or competencies, showcase and build pride through "learning to learn" guidelines and practical design exercises.

Matching educational resources could facilitate learners to understand how to combine what they have learned from school and work, apply theoretical knowledge to actual practices, and then bring the challenges and insights encountered at work back to the learning environment. It can enhance teaching and learning in school, achieve the relative integration of supply of "subject" and demand of "subject" and improve the quality of educational products and market competitiveness.

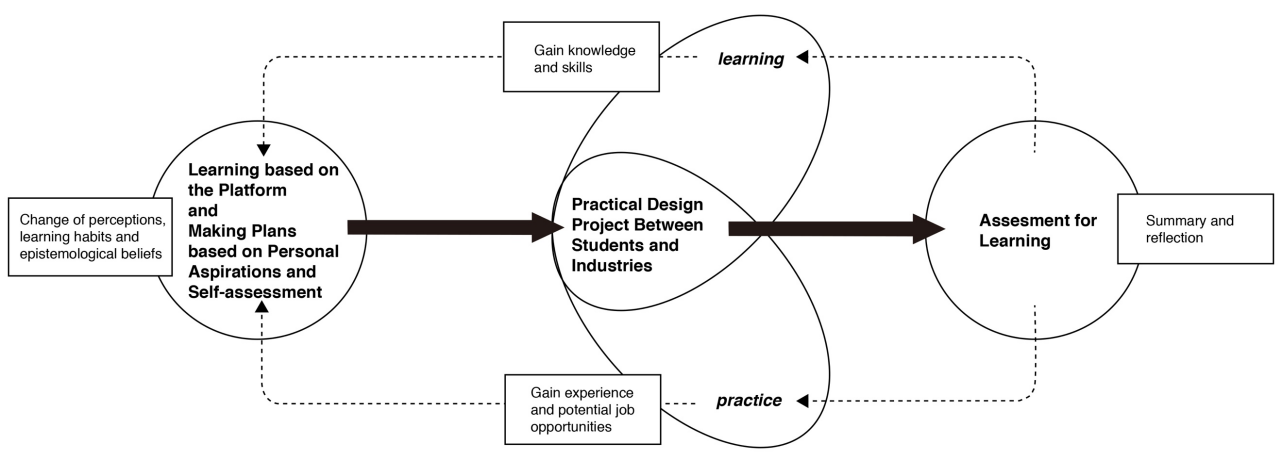

Figure 1. Proposed model for platform.

\section{Interactive Platform Design}

Building a sustainable interactive online platform for school-enterprise cooperation is about the integration and use of enterprise resources. On the other hand, students and teachers can also learn and practice on the platform during and beyond the project period. This platform consists of three components:

- a "learning to learn" component which facilitates students to learn, think, plan and so on and so forth; 
- $\quad$ an interactive platform that integrates enterprise resources and displays the works of students as a collaborative effort; and

- measures to evaluate the progress of the students and facilitate self-reflection.

\subsection{Learning to Learn}

We established a learning workflow (Figure 2) which shows the important milestones for completing a project. It is a clear and useful resource for students to understand how to engage in a "learning to learn" process step-by-step and receive guidance. This resource for selflearning consists of three units: Unit 1. Motivation: What is it? (Why does motivation matter? Why is it hard to get motivated? What are some strategies for boosting motivation?) Unit 2. Cultivating Metacognition. (What is the metacognitive concept and theory? Metacognition vs. cognition. Metacognition in design. Metacognitive strategies.) Unit 3. Gain Knowledge of Practical Design. (Design methods. Know more about the industry. Recommendations). The platform also provides learning resources for teachers to co-learn and help their students.

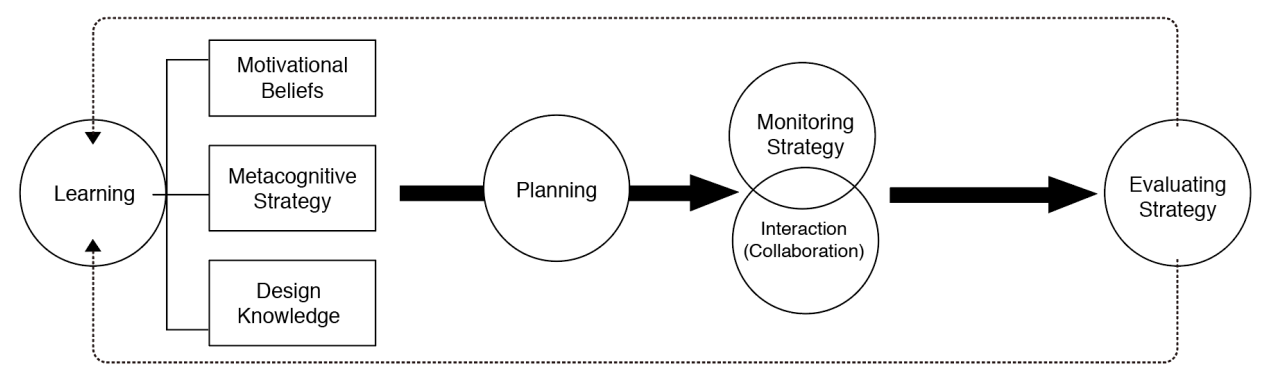

Figure 2. Learning workflow.

\subsection{Interactive Platform}

The interactive platform provides the opportunity for students to do real life design. They can communicate and work with the company on the online platform. It is not just practice, but actual design work for the industry. Students can provide personal details, such as a profile, their portfolio and résumé on the platform to promote themselves (see Figure 3). By participating in school-enterprise cooperation activities, a company can cultivate new talent and receive new ideas. The collaboration is also conducive to brand marketing and promotion, so this platform benefits companies too. Companies can distribute their information and design projects on the platform for students and teachers who are interested and further communicate with them (see Figure 4). Students can also carry out some background research on the company to accommodate their corporate climate. 


\title{
About Our Students
}

\begin{abstract}
Design students of The Hong Kong Polytechnic University Institute of Textiles and Clothing are mainly come from the fellow 3 area: knitwear design, fashion design and intimate apparel design. Under professional education training, students possess solidate professional and fundamental skills, as well as critical and creative thinking ability. Also, they are all-round developed design talents with foresight and global vision.
\end{abstract}

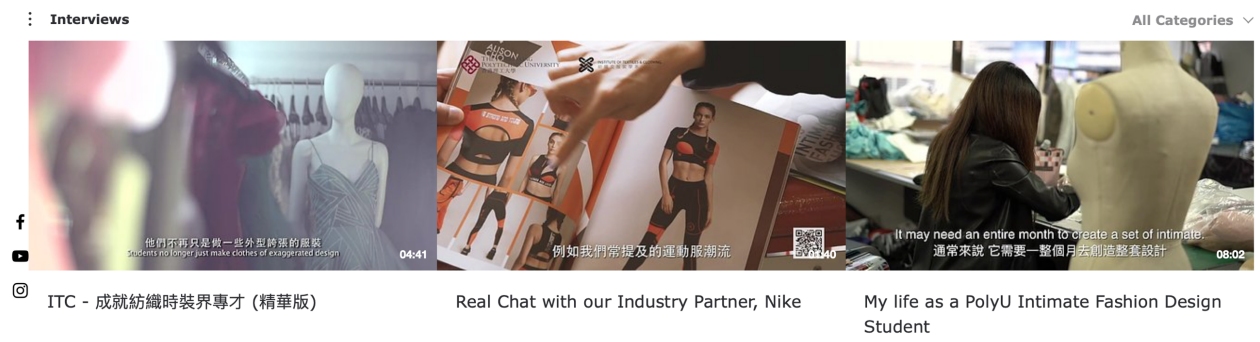

Figure 3. Student particulars on the platform.

\section{Companies Information}

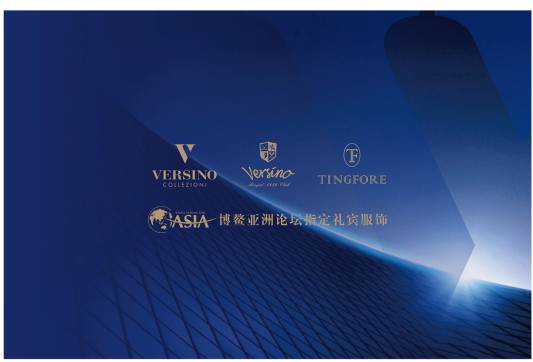

VERSINO

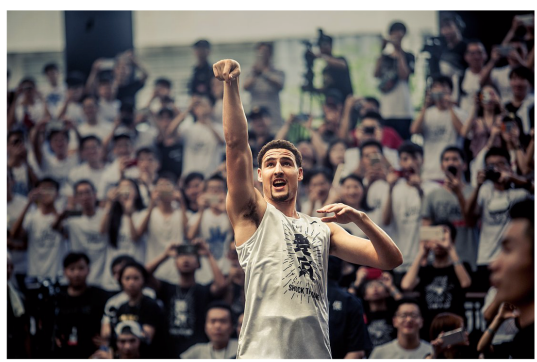

ANTA

Figure 4. Company information.

\subsection{Evaluation}

Metacognition defines evaluation as assessing the recent knowledge status of learners, which involves tracking their attention span as they study, and self-testing and enquiring, which are ongoing (before, within and after a task). Lawanto (2010), Choi (2006) indicated that "the purpose of metacognition evaluation is to encourage students to think about such problems 
(e.g. poor performance) by reflecting upon themselves through self-evaluation." According to Hargrove (2007), the implementation of evaluation includes the following elements:

- Evaluating goal achievement

- Judging the results accurately and adequately

- Evaluating the appropriateness of procedures used

- Assessing how obstacles/errors are managed

- Evaluating the efficiency of a plan and its execution

Established data analysis strategies can be used to evaluate the progress of students, e.g. through surveys, interviews, observations, or reflective design portfolios. Not only do these confirm the effectiveness of this project, but also obtain feedback to improve the platform. Figure 5 shows the main evaluation scope of student learning in this stage.

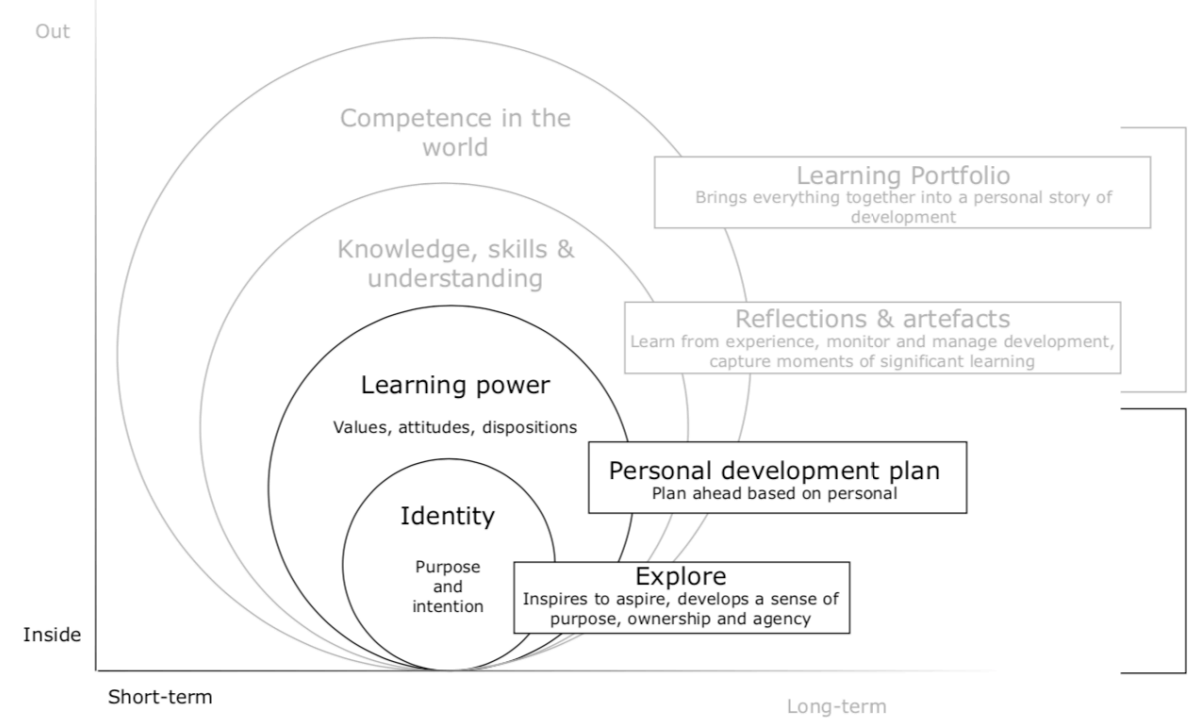

Figure 5. Main evaluation scope.

\section{Conclusions}

"Learning to learn" provides a much needed overview and international guide to the field of learning to learn from a multidisciplinary lifelong and lifewide perspective. A wealth of research has been flourishing on this key educational goal in recent years. Internationally, it is not only considered to be one of the key competencies needed to compete in the global economy, but also a crucial factor for individual and social well-being (Crick, Stringher \& Ren, 2014) Encouraging learning to learn should thus be one of the primary objectives of today's education systems. 
The world is changing rapidly nowadays, with the rapid development of computer network technology. Also, COVID-19 has changed lifestyle, work, learning, etc. The model of schoolenterprise cooperation has also changed from offline to online. As such, an interactive platform would offer great convenience to enterprises and universities, and along with the application of the learning to learn theory, contribute to advancing practical design education.

\section{Acknowledgements}

The authors would like to acknowledge financial support from The Hong Kong Polytechnic University for Teaching Development Grant (TDG) 2019-22.

\section{References}

教育統籌委員會（2000）。終身學習，全人發展：香港教育制度改革建議. 香港：教 育統籌委員會.

彭新強，李傑江（2008）. 元認知：學會學習的核心. 香港：中文大學教育學院香港 教育研究所.

Lawanto, O. (2010). Students' Metacognition During an Engineering Design Project. Performance Improvement Quarterly, 23(2), 117-136. doi: https://doi.org/10.1002/piq.20084.

Choi, J. Y. (2006). Metacognitive Evaluation Method in Consecutive Interpretation for Novice Learners. Meta, 51(2), 273-283. doi: https://doi.org/10.7202/013256ar

Hargrove, R. A. (2007). Creating Creativity in the Design Studio: Assessing the impact of metacognitive skill development on creative abilities (Doctoral dissertation). North Carolina State University.

Crick, R. D., Stringher, C., \& Ren, K. (2014). Learning to learn: International perspectives from theory and practice. London: Routledge.

Kavousi, S., Miller, P. A., \& Alexander, P. A. (2020). Modeling Metacognition in Design Thinking and Design Making. International Journal of Technology and Design Education, 30(4), 709-735. doi: 10.1016/j.sbspro.2014.09.194

Kurt, M., Kurt, S. (2017). Improving Design Understandings and Skills through Enhanced Metacognition: Reflective Design Journals. The International Journal of Art \& Design Education, 36(2), 226-238. doi: 10.1111/jade.12094

Erika, A. (2016). Managing Yourself: Learning to learn. Harvard Business Review.

Sagitova, R. (2014). Students' Self-education: Learning to learn across the lifespan. Procedia-social and Behavioral Sciences, 152, 272-277. doi: 10.1016/j.sbspro.2014.09.194

James, M., McCormick, R. (2009). Teachers learning how to learn. Teaching and Teacher Education, 25(7), 973-982. doi: 10.1016/j.tate.2009.02.023 
Severson, D. I., Robert, G. K. (2006). Learning How to Learn from Each Other: The educational possibilities of a company work improvement team (Doctoral dissertation). The Faculty of the Graduate School of Education of Harvard University.

Cook, J. W. (2019). Sustainability, Human Well-being, and the Future of Education. Cham: Springer.

Mayer, R. E. (2019). How to be a successful student: 20 study habits based on the science of learning. New York, NY: Routledge.

Sorger, R., Udale, J. (2012). Fundamentals of Fashion Design. London, GBR: AVA Publishing.

Papleontiou-louca, E. (2003). The Concept and Instruction of Metacognition. Teacher Development, 7(1), 9-30. doi: 10.1080/13664530300200184 